\title{
Towards reconstruction of the flow duration curve: development of a conceptual framework with a physical basis
}

\author{
Y. Yokoo ${ }^{1}$ and M. Sivapalan ${ }^{2,3}$ \\ ${ }^{1}$ Faculty of Symbiotic Systems Science, Fukushima University, Fukushima, Japan \\ ${ }^{2}$ Department of Civil and Environmental Engineering, University of Illinois at Urbana-Champaign, Illinois, USA \\ ${ }^{3}$ Department of Geography, University of Illinois at Urbana-Champaign, Illinois, USA
}

Received: 28 March 2011 - Published in Hydrol. Earth Syst. Sci. Discuss.: 20 April 2011

Revised: 24 August 2011 - Accepted: 1 September 2011 - Published: 9 September 2011

\begin{abstract}
In this paper we investigate the climatic and landscape controls on the flow duration curve (FDC) with the use of a physically-based rainfall-runoff model. The FDC is a stochastic representation of the variability of runoff, which arises from the transformation, by the catchment, of within-year variability of precipitation that can itself be characterized by a corresponding duration curve for precipitation (PDC). Numerical simulations are carried out with the rainfall-runoff model under a variety of combinations of climatic inputs (i.e. precipitation, potential evaporation, including their within-year variability) and landscape properties (i.e. soil type and depth). The simulations indicated that the FDC can be disaggregated into two components, with sharply differing characteristics and origins: the FDC for surface (fast) runoff (SFDC) and the FDC for subsurface (slow) runoff (SSFDC), which included base flow in our analysis. SFDC closely tracked PDC and can be approximated with the use of a simple, nonlinear (threshold) filter model. On the other hand, SSFDC tracked the FDC that is constructed from the regime curve (i.e. mean monthly runoff), which can be closely approximated by a linear filter model. Sensitivity analyses were carried out to understand the climate and landscape controls on each component, gaining useful physical insights into their respective shapes. In particular the results suggested that evaporation from dynamic saturated areas, especially in the dry season, can contribute to a sharp dip at the lower tail of the FDCs. Based on these results, we develop a conceptual framework for the reconstruction of FDCs in ungauged basins. This framework partitions the FDC into: (1) a fast flow component, governed by a filtered version of PDC, (2) a slow flow component governed by the regime curve, and (3) a correction to SSFDC to capture the effects of high evapotranspiration (ET) at low flows.
\end{abstract}

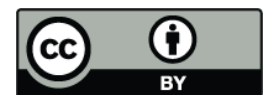

Correspondence to: Y. Yokoo

(yokoo@sss.fukushima-u.ac.jp)

\section{Introduction}

The flow duration curve (FDC) is a representation of the frequency distribution of streamflow of a specific time period (normally daily, but can also be hourly) (see Vogel and Fennessey, 1994, 1995; Smakhtin, 2001). It is effectively an alternative representation of the cumulative distribution function of daily (or hourly) streamflow. Hydrologists have traditionally analyzed the FDC using purely graphical representations (Ward and Robinson, 1990), or using stochastic models that focus on fitting appropriate statistical distributions and estimating associated parameters (see most recent work by Castellarin et al., 2004a; Iacobellis, 2008). Many of the past efforts have focused on relating the characteristics of the FDCs (e.g. shape measures or parameters of the statistical distributions, as the case may be), to the catchment's climatic and physiographic characteristics, to assist in regionalization of the FDCs and as a precursor to estimation in ungauged catchments.

Work over the past few decades has contributed to the accumulation of considerable empirical knowledge on the effects of a single or several characteristics of watersheds upon the shape of FDCs. Musiake et al. (1975) investigated the effects of geology and climate type on the shape of FDCs in Japanese mountainous watersheds. Ward and Robinson (1990) provide a summary of the effects of dominant soil types on FDCs in UK catchments. Burt and Swank (1992) investigated the effects of vegetation type on the FDCs. Sefton and Howarth (1998) explored the effects of morphometric, soil, land use, and climate properties of watersheds on the FDCs in the UK. Castellarin et al. (2004b) presented a regional statistical model to construct FDCs based on watershed morphology and climate characteristic in Italian catchments. Despite such empirical results we have not yet succeeded in developing a comprehensive understanding of the relative contributions of climatic and watershed characteristics on the shape of the FDCs, especially towards establishing

Published by Copernicus Publications on behalf of the European Geosciences Union. 
globally applicable relationships. In other words, if one were to think of the several empirical studies reviewed above as pieces of a jigsaw puzzle, we have not yet acquired the understanding and the methodology to complete that puzzle. The work presented in this paper is a small step in developing a general process-based characterization of the FDC, fully reflecting the complex interactions between climate (i.e. precipitation and radiation) and catchment physiographic characteristics that contribute to the generation of runoff by many different mechanisms.

In recent times there have been several promising efforts that approach FDCs from a process perspective. Castellarin et al. (2004a) proposed a new stochastic representation of FDCs to reproduce the observed variance of annual flows. Botter et al. (2007a) presented the mathematical formalisms for the derivation of the probability distribution (which is equivalent to FDCs), associated with within-year variation of the baseflow component of daily streamflow. Botter et al. (2007b) derived the FDCs using a stochastic-dynamic model that captured the interaction of within-year sequences of precipitation events with a simple lumped model of subsurface drainage, which is governed by a field capacity threshold and a characteristic catchment residence time. The model was successfully tested in a number of catchments across the United States. Yilmaz et al. (2008) approached the same question with the use of the Sacramento Soil Moisture Accounting Model (SAC-SMA) and explored, through sensitivity analyses, the effect of the upper layer tension water capacity (which is a model parameter) and other model parameters on the shape of FDCs, including the relative extents of the high flow segment and the low flow segment, and the slope of intermediate flow segment. Botter et al. (2009) later extended their probabilistic model to explain observed catchment streamflow regimes across the United States. Muneepeerakul et al. (2010) further extended the stochastic-dynamic model of Botter et al. (2007a,b, 2009) to include fast runoff processes, and in this way presented a stochastic framework to mimic the within-year variability of both fast and slow flow components of the FDCs in a number of US catchments.

The work presented in this paper can be viewed as a further extension of the work of Botter et al. (2007a,b, 2009) and Muneepeerakul et al. (2010) but is different from their work in several ways: (i) this numerical modeling study will use a more advanced physically-based, continuous water balance model that includes runoff generation by several mechanisms; (ii) being a numerical model, the simulations will be able to capture the effects of not only the randomness of precipitation events (i.e. the Poisson assumption made in Botter et al., 2007a,b) but also, explicitly, the effects of systematic seasonal variability of both precipitation and potential evaporation, which together govern the variability of antecedent soil moisture conditions and their effects on runoff generation; and (iii) the model used is a lumped quasi-2D model, and does include lateral flow processes (e.g. saturation excess overland flow and subsurface stormflow), and can therefore be used to assess their relative effects on the shape of the FDCs.

The water balance model used here is taken from Yokoo et al. (2008). This model was developed on the basis of governing equations for mass and momentum balance derived at the scale of a representative elementary watershed (REW), which have been the basis of numerous distributed modeling efforts (e.g. Zhang and Savenije, 2005; Zehe et al., 2006; Lee et al., 2007; Li et al., 2011; Li and Sivapalan, 2011). Previous applications of the model used here have involved the exploration of (1) mean annual water balance within the Budyko (1974) framework (Reggiani et al., 2000), and (2) mean monthly runoff (i.e. regime curve) (Yokoo et al., 2008), with both studies including the partitioning into surface and subsurface runoff as well. The current paper thus represents a further application of the model to develop insights into the FDC. The main aims of the paper are: (1) To generate insights into the shape of the FDCs, and to determine the relative controls of climate and landscape properties on the FDCs, including its various components; (2) to develop a conceptual framework that can be utilized, in combination with the insights gained into the climate and landscape controls on the FDCs, to help reconstruct FDCs in ungauged basins.

The approach adopted in this paper to achieve these aims includes the use of the adopted water balance model under various combinations of climatic and catchment physiographic parameters to explore the sensitivity of the shapes of the FDCs to these parameter combinations. We examine the causes for these sensitivities through a detailed examination of how the variability in the climatic inputs propagates through the catchment system and the various transformations that take place within various subsystems. On the basis of these results we draw up broad conclusions about the controls of climatic and physiographic characteristics on the shapes of the FDCs. Note that, for the present, this is a purely theoretical study and has the disadvantage that the ideas generated through this study have not been tested on observed data in actual catchments. However, our intention is that the framework we will develop here, through generating plausible hypotheses, would be a necessary precursor to systematic empirical analysis that could help validate these hypotheses through the use of empirical observations. Towards this end we do present several case studies where we present estimated FDCs of precipitation, total streamflow as well the fast and slow components of streamflow in actual catchments, to demonstrate in a preliminary manner the validity and potential use of the proposed framework. Rigorous testing of these ideas and the climatic and landscape controls on the FDCs in actual catchments in a regional context is left for further research. 


\section{Methodology}

The key components of the methodology involve the use of (i) a stochastic rainfall model to generate synthetic rainfall event sequences, under different assumed climates, and (ii) the lumped quasi-2-D, physically based rainfall-runoff model. The two models are used in sequence for a variety of combinations of soils and climate to generate runoff time series (including surface and subsurface runoff components) from which the FDCs are derived, including its two components. Next we present the brief summaries of the rainfall and rainfall-runoff models.

\subsection{Stochastic rainfall model}

We employ an event-based stochastic model of precipitation time series developed by Robinson and Sivapalan (1997) to generate multiple random realizations of synthetic precipitation inputs. This model is capable of reproducing multi-scale temporal variability of rainfall intensities, including random within-storm and between-storm variability, the parameters of which can, if needed, vary seasonally in a deterministic manner. Both storm durations and inter-storm periods are assumed to follow the exponential distribution, the parameters of which also vary sinusoidally over the year. Mean rainfall intensities during storms are assumed to follow a conditional gamma distribution, subject to the chosen storm duration, the parameters of which could also vary sinusoidally over the year. The mean storm intensity is further disaggregated to hourly intensity patterns (within-storm patterns) using stochastically generated mass curves (Huff, 1967; Chow et al., 1988). This disaggregation is carried out with the use of the random cascade model (Koutsoyiannis and FoufoulaGeorgiou, 1993): the random weights chosen to sequentially disaggregate the rainfall depth at finer time steps are assumed to follow the beta distribution.

Details of the synthetic rainfall model can be found in the original paper by Robinson and Sivapalan (1997). For convenience, the model parameters used for the simulations reported in this paper are the same as those in Table 2 of Robinson and Sivapalan (1997), derived for the raingauge at Salmon Creek in Western Australia (which is used mainly for convenience). In this study we generated hourly rainfall intensities for a period of 13 years, which were then rescaled so that the mean annual rainfall over the 13 year period becomes approximately $1000 \mathrm{~mm}$, consistent with the notion that this is a completely theoretical study. In the simulation results presented in this paper, we used 3 year-long segment of the synthetic rainfall timeseries, which includes the effect of inter-annual variability of annual rainfall, as well withinyear variability at the event scale.

The attraction of using such a model for generating synthetic precipitation inputs is that it allows us to perform diagnostic analyses whereby we can switch on and off different components of the natural variability, and investigate their

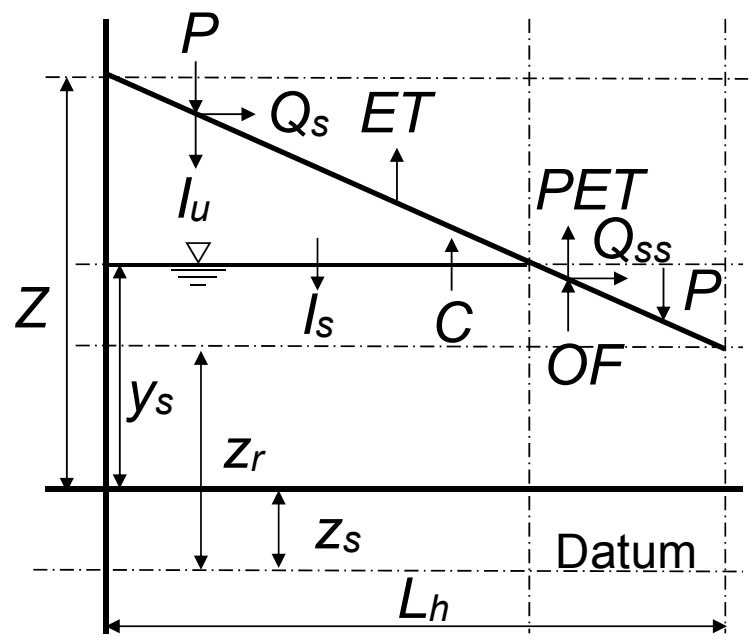

Fig. 1. Conceptual drawing of Reggiani et al.'s (2000) REW-scale water balance model: $P$ : Precipitation, ET: Evapotranspiration, PET: Potential evapotranspiration, $Q_{\mathrm{s}}$ : Surface runoff, $Q_{\mathrm{ss}}$ : Subsurface runoff, $I_{u}$ : Infiltration from the ground surface, $I_{S}$ : Infiltration to the saturated zone, $C$ : Capillary rise, OF: Outflow from saturated zone, $Z$ : Average elevation of ground surface from datum, $z_{\mathrm{r}}$ : Average elevation of channel bed with respect to datum, $z_{\mathrm{s}}$ : Average elevation of the bottom surface of the REW with respect to datum, $y_{\mathrm{s}}$ : Average thickness of saturated zone, $L_{\mathrm{h}}$ : Averaged horizontal length of one side of REW.

effects on the shape of the FDCs. This is a significant advantage over the use of historical data.

\subsection{Water balance model}

For the rainfall-runoff simulations in this paper, we employ the simple, lumped and physically based quasi-2-D water balance model previously used by Yokoo et al. (2008), which was an extension of the model originally developed by Reggiani et al. (2000). The description presented is taken from Yokoo et al. (2008) for completeness. Figure 1 presents a schematic description of the model. To keep the model simple, the model structure has been simplified to include just two zones, an unsaturated zone and a saturated zone below it. We used this model as a hillslope to sub-basin scale runoff generator only; river routing is not explicitly included in the model. Within this simple structure, and the associated governing equations, the model monitors as state variables the saturation degree in the unsaturated zone, the saturated zone thickness, and the saturated and unsaturated area fractions (as geometric functions of the saturated area thickness). The model predicts key physical processes such as runoff generation by infiltration excess, saturation excess and subsurface stormflow, as well recharge, capillary rise and evaporation and transpiration through root water uptake. Further details about the model can be found in the original paper by Reggiani et al. (2000) and also in the subsequent paper by Yokoo 
et al. (2008). In this paper we only give a brief outline of the model and the parameter sets used in the simulations reported here.

\subsubsection{Governing equations}

The water balance model by Reggiani et al. (2000) consists of three coupled governing equations: mass balance in the unsaturated zone, momentum balance in the unsaturated zone, and mass balance in the saturated zone, as shown in Eqs. (1)(3), respectively.

$$
\begin{aligned}
& \underbrace{\rho \varepsilon \frac{\mathrm{d}}{\mathrm{d} t}\left(s_{\mathrm{u}} y_{\mathrm{u}} \omega_{\mathrm{u}}\right)}_{\text {Change in unsaturated storage }} \\
& =\underbrace{\min \left\{\rho P \omega_{\mathrm{u}}, \frac{\rho K_{\mathrm{s}} \omega_{\mathrm{u}}}{\Lambda_{\mathrm{u}}}\left[\frac{1}{2} y_{\mathrm{u}}-\psi_{\mathrm{u}}\right]\right\} \cdot \delta\left[0, t_{\mathrm{r}}\right]}_{\text {Infiltration }} \\
& +\underbrace{\rho \varepsilon \omega_{\mathrm{u}} v_{\mathrm{u}}}_{\text {Percolation or capillaryrise }}
\end{aligned}
$$$$
-\underbrace{\rho \omega_{\mathrm{u}} \frac{1}{R}\left(\tanh 5 s_{\mathrm{u}}\right)\left(1.0+R^{-5}\right)^{-(1 / 5)} \mathrm{PET} \cdot \delta\left[t_{\mathrm{r}}, t_{\mathrm{m}}\right]}_{\text {Evapotranspiration }}
$$$$
-\underbrace{\varepsilon \rho g s_{\mathrm{u}} y_{\mathrm{u}} \omega_{\mathrm{u}}}_{\text {Gravitation }}
$$$$
\text { Gravitational force }
$$$$
+\quad \underbrace{\varepsilon \rho g s_{\mathrm{u}} \omega_{\mathrm{u}}\left[\frac{1}{2} y_{\mathrm{u}}-\psi_{\mathrm{u}}\right]}
$$

Force acting onthe water across the land surface

$$
\begin{aligned}
& =\underbrace{K^{-1} \varepsilon \rho g y_{\mathrm{u}} \omega_{\mathrm{u}} v_{\mathrm{u}}}_{\text {Resistance force }} \\
& \underbrace{\rho \varepsilon \frac{\mathrm{d}}{\mathrm{d} t}\left(y_{\mathrm{s}} \omega_{\mathrm{s}}\right)}_{\text {Change in the saturated storage }}=-\underbrace{\rho \varepsilon \omega_{\mathrm{u}} v_{\mathrm{u}}}_{\text {Percolation or capillary rise }}
\end{aligned}
$$$$
-\underbrace{\frac{\rho K_{\mathrm{s}} \omega_{\mathrm{o}}}{\cos \left(\gamma_{\mathrm{o}}\right) \Lambda_{\mathrm{s}}} \frac{1}{2}\left(y_{\mathrm{s}}-z_{\mathrm{r}}+z_{\mathrm{s}}\right)}_{\text {Outflow across seepage faces }} .
$$

The function $\delta\left[0, t_{\mathrm{r}}\right]\left(\delta\left[t_{\mathrm{r}}, t_{\mathrm{m}}\right]\right)$ in Eq. (1) is equal to $1(0)$ if time $t$ in a meteorological period, which consists of a storm duration and the subsequent inter-storm period, falls between $0\left(t_{\mathrm{r}}\right)$ and $t_{\mathrm{r}}\left(t_{\mathrm{m}}\right)$ during a storm period, and is zero (Eq. 1) otherwise during the inter-storm period. The variables $s_{\mathrm{u}}, y_{\mathrm{u}}, \omega_{\mathrm{u}}, \Lambda_{\mathrm{u}}, \psi_{\mathrm{u}}, v_{\mathrm{u}}, K, P$, and PET are, respectively, saturation degree in the unsaturated zone, average thickness of the unsaturated zone, unsaturated surface area fraction, a characteristic length scale for infiltration, pressure head in the unsaturated zone, upward velocity in the unsaturated zone, unsaturated hydraulic conductivity, precipitation intensity, and a seasonally-varying potential evaporation. The variables $y_{\mathrm{s}}, \omega_{\mathrm{s}}, \omega_{\mathrm{o}}, \gamma_{\mathrm{o}}$, and $\Lambda_{\mathrm{s}}$ are, respectively, the average thickness of the saturated zone, area fraction of the saturated zone kept at 1.0 based on the assumption that a saturated zone exists everywhere below the water table of a REW, the saturated surface area fraction is assumed to vary with the saturation degree of the unsaturated zone, slope angle of the overland flow plane with respect to horizontal, and a typical length scale for seepage outflow. The definitions of the other variables used in these equations are summarized in Table 1 as well as in the appendix of Reggiani et al. (2000). These equations contain 7 unknowns, and therefore 4 additional closure relations are required. Most of those are simple geometric relations, but the parameterization of the seepage area fraction $\omega_{0}$ is a non-trivial one requiring further assumptions, as outlined below:

$$
\begin{aligned}
& \omega_{\mathrm{o}}=\frac{y_{\mathrm{s}}-z_{\mathrm{r}}+z_{\mathrm{s}}}{Z-z_{\mathrm{r}}+z_{\mathrm{s}}} \\
& \dot{\omega}_{\mathrm{o}}=-\dot{\omega}_{\mathrm{u}} .
\end{aligned}
$$

In Eq. (4), $Z$ is the average thickness of the subsurface zone, $z_{\mathrm{r}}$ is channel bed elevation with respect to a datum, $z_{\mathrm{s}}$ is the average elevation of the bottom surface of the REW with respect to the datum, $y_{\mathrm{s}}$ is the average thickness of the subsurface zone along the vertical, and $\omega_{\mathrm{u}}$ is the area fraction of the unsaturated zone.

To solve the governing equations, we need constitutive relationships regarding the hydraulic properties of the soil. We use the VK model for hydraulic conductivity (Kosugi, 1994) for the water retention curve, which has the advantage that it does not have a discontinuous point near saturation, contains only three physical parameters, and thus permits easy calibration to measured water retention data. Equations (6) or (7) are the functional forms of the VK model,

$\psi_{\mathrm{u}}= \begin{cases}\psi_{\mathrm{c}}-\left(\psi_{\mathrm{c}}-\psi_{0}\right) \cdot\left\{\frac{\left(s_{\mathrm{u}}\right)^{-1 / m}-1.0}{m}\right\}^{1.0-m} & \left(s_{\mathrm{u}}<1.0\right) \\ \psi_{\mathrm{c}} & \left(s_{\mathrm{u}}=1.0\right)\end{cases}$

$s_{\mathrm{u}}= \begin{cases}1 /\left\{1+m\left(\frac{\psi_{\mathrm{c}}-\psi_{\mathrm{u}}}{\psi_{\mathrm{c}}-\psi_{0}}\right)^{1 /(1-m)}\right\}^{m} & \left(\psi_{\mathrm{u}}<\psi_{\mathrm{c}}\right) \\ 1.0 & \left(\psi_{\mathrm{u}} \geq \psi_{\mathrm{c}}\right)\end{cases}$

where $\psi_{\mathrm{c}}, \psi_{0}$, and $m$ are bubbling pressure, capillary pressure at the inflection point on the $s_{\mathrm{u}}-\psi_{\mathrm{u}}$ curve, and dimensionless parameter, respectively. For the unsaturated hydraulic conductivity $K$, we use Eq. (8) from Reggiani et al. (2000), which was in turn taken from (Brutsaert, 1966),

$K=K_{\mathrm{s}} \cdot\left(s_{\mathrm{u}}\right)^{\lambda}$

where $\lambda$ is pore-disconnectedness index. 
Table 1. Meaning, values and the ranges of model parameters used in the numerical experiments.

\begin{tabular}{|c|c|c|c|c|}
\hline Group & Name & Description (unit) & & Value and the range \\
\hline \multirow[t]{3}{*}{ Climate } & $P_{\mathrm{a}}$ & Annual precipitation (mm) & & 1000 (mean) \\
\hline & & Dryness index & & $0.5(0.0-2.0)$ \\
\hline & $\mathrm{PET}_{\mathrm{a}}$ & Potential evapotranspiration (mm) & & $P_{\mathrm{a}} \cdot R$ \\
\hline \multirow[t]{14}{*}{ Geographic } & $Z$ & Depth of soil layer (m) & & $5-20$ \\
\hline & $z_{\mathrm{r}}$ & Average elevation of channel bed from datum (m) & & $3.0-7.0$ \\
\hline & $z_{\mathrm{s}}$ & Average elevation of the bottom end of REW from datum (m) & & 0 \\
\hline & $y_{\mathrm{s}}$ & Average thickness of saturated zone (m) & & $Z-y_{\mathrm{u}} \omega_{\mathrm{u}}, 0.5 Z\left(\right.$ ini. $\left.^{3}\right)$ \\
\hline & $y_{\mathrm{u}}$ & Average thickness of unsaturated zone (m) & & $\left(Z-y_{\mathrm{s}}\right) / \omega_{\mathrm{u}}$ \\
\hline & $\omega_{\mathrm{u}}$ & Unsaturated surface area fraction of unsaturated zone & & $\left(Z-y_{\mathrm{s}}\right) / y_{\mathrm{u}}$ \\
\hline & $\omega_{\mathrm{o}}$ & Saturated surface area fraction of unsaturated zone & & $1-\omega_{\mathrm{u}}$ \\
\hline & $\omega_{\mathrm{s}}$ & Horizontal area fraction of saturated zone & & 1 \\
\hline & $s_{\mathrm{u}}$ & Saturation degree of unsaturated zone & & $0.5\left(\right.$ ini. $\left.^{3}\right)$ \\
\hline & $\Lambda_{\mathrm{u}}$ & Typical length scale for infiltration & & $s_{\mathrm{u}} y_{\mathrm{u}}$ \\
\hline & $\Lambda_{\mathrm{S}}$ & Typical length scale for seepage outflow (m) & & 10 \\
\hline & $\gamma_{\mathrm{o}}$ & Slope gradient of the overland flow plane, which is assumed to be nearly flat. & & 0.0 \\
\hline & $L_{\mathrm{h}}$ & Representative hillslope length of a REW in Fig. 1 (m) & & 500 \\
\hline & $G$ & Slope gradient of a REW & & $0.002-0.010$ \\
\hline \multirow[t]{21}{*}{ Soil } & $K$ & Hydraulic conductivity $\left(\mathrm{m} \mathrm{s}^{-1}\right)$ & & - \\
\hline & $K_{\mathrm{S}}$ & Saturated hydraulic conductivity $\left(\mathrm{m} \mathrm{s}^{-1}\right)^{1}$ & Silty loam & $3.4 \times 10^{-6}$ \\
\hline & & & Sandy loam & $3.4 \times 10^{-5}$ \\
\hline & & & Sand & $8.6 \times 10^{-5}$ \\
\hline & $\lambda$ & Pore-disconnectedness index ${ }^{1}$ & Silty loam & 4.7 \\
\hline & & & Sandy loam & 3.6 \\
\hline & & & Sand & 3.4 \\
\hline & $\varepsilon$ & Porosity ${ }^{1}$ & Silty loam & 0.35 \\
\hline & & & Sandy loam & 0.25 \\
\hline & & & Sand & 0.20 \\
\hline & $m$ & Dimensionless parameter related to the width of the pore radius distribution ${ }^{2}$ & Silty loam & 0.44 \\
\hline & & & Sandy loam & 0.70 \\
\hline & & & Sand & 0.77 \\
\hline & $\psi_{\mathrm{c}}$ & Bubbling pressure $(\mathrm{m})^{2}$ & Silty loam & -0.20 \\
\hline & & & Sandy loam & -0.10 \\
\hline & & & Sand & -0.10 \\
\hline & $\psi_{0}$ & Capillary pressure at the inflection point on the $\theta-\psi$ curve $(\mathrm{m})^{2}$ & Silty loam & -0.30 \\
\hline & & & Sandy loam & -0.25 \\
\hline & & & Sand & -0.16 \\
\hline & $\psi_{\mathrm{u}}$ & pressure head in the unsaturated zone & & - \\
\hline & $v_{\mathrm{u}}$ & Velocity in the unsaturated zone $\left(\mathrm{m} \mathrm{s}^{-1}\right)$, positive when directed upward. & & - \\
\hline \multirow[t]{3}{*}{ Others } & $\rho$ & Water density $\left(\mathrm{kg} \mathrm{m}^{-3}\right)$ & & 1000 \\
\hline & $g$ & Gravitational acceleration $\left(\mathrm{m} \mathrm{s}^{-2}\right)$ & & 9.80 \\
\hline & $t$ & Time & & - \\
\hline
\end{tabular}

The ${ }^{1}$ indicates parameters are taken from Bras (1990), and the ${ }^{2}$ indicates the parameters are obtained by calibration. The calibration involved manually adjusting the parameters in Kosugi's (Kosugi, 1994) water retention curve (VK model) with those from the Brooks-Corey model (Brooks and Corey, 1966) and the parameters in Bras (1990) as much as possible. The ${ }^{3}$ indicates initial condition.

\subsubsection{Numerical solution of governing equations and water balance calculations}

In solving the governing equations, we need to provide initial conditions for the saturation degree in the unsaturated zone $s_{\mathrm{u}}$ and water table thickness $y_{\mathrm{s}}$, in addition to parameter settings for soil properties, climatic inputs, and the two geometric parameters of $\gamma_{\mathrm{o}}$ and $\Lambda_{\mathrm{s}}$ in Table 1. Arbitrary initial values for soil moisture and water table depth are appropriate so long they are not very different from physically acceptable values. We set the initial values of 0.5 for $s_{\mathrm{u}}$ and $z_{\mathrm{r}}-z_{\mathrm{s}}$ for $y_{\mathrm{s}}$, in common to all the numerical experiments. The soil hydraulic properties are taken from the literature (Bras, 1990). As in Reggiani et al. (2000) the two geometric parameters, $\gamma_{\mathrm{o}}$ 
and $\Lambda_{\mathrm{s}}$, are taken to be 0.0 and $10 \mathrm{~m}$, respectively. For the climatic inputs, we assumed the annual rainfall to be $1000 \mathrm{~mm}$ and annual potential evaporation was then chosen on the basis of the climatic dryness index $R$, the ratio of annual potential evaporation over annual precipitation, given by:

$R=\frac{\text { PET }_{\mathrm{a}}}{P_{\mathrm{a}}}$

where PET $\mathrm{a}$ and $P_{\mathrm{a}}$ are annual evaporation $(\mathrm{m})$ and annual precipitation $(\mathrm{m})$, respectively. For reference, Table 1 presents the list of all the parameters and the ranges of values used in this paper.

In this paper we utilize a fourth-order Runge-Kutta integration method for solving the coupled governing equations simultaneously. Firstly, we gave initial condition for $s_{\mathrm{u}}$ and $y_{\mathrm{S}}$ to solve Eq. (2) as mentioned above. Secondly, we solved Eqs. (1) and (3) to obtain $s_{\mathrm{u}}$ and $y_{\mathrm{s}}$ in the next step of the Runge-Kutta integration method. The simulations were carried out for a period of 13 years with a time step of $5 \mathrm{~min}$. Only the last 3 years of the runoff time series produced by the model were used to estimate the FDCs; in this way, the effect of initial conditions on the resulting FDCs can be neglected. Although we cannot completely remove the effect of initial conditions, we visually confirmed that the effect was negligible. We also confirmed that seasonal variability is strong enough in the 3 year long runoff time series whenever climatic seasonality is active in the climatic setting, through setting the seasonal amplitudes of $P$ and PET to be respectively equal to their mean values.

\subsection{Setup for the numerical experiments}

The main analysis we perform in this paper is a series of numerical experiments with the numerical model of water balance. These experiments take the form of sensitivity analyses with the rainfall-runoff model to investigate the controls of climate, soil, and topography on the shapes of the FDCs, including the SFDCs (surface runoff) and SSFDCs (subsurface stormflow). Average annual precipitation $P_{\mathrm{a}}$ was set to $1000 \mathrm{~mm}$ in all of the simulations. The synthetically generated precipitation time series $P(t)$ based on the stochastic model of Robinson and Sivapalan (1997) are used in all the simulations. Dryness index $R$ was varied from 0.5 to 1.5 by changing the annual potential evapotranspiration $\operatorname{PET}(t)$, with both $P(t)$ and $\operatorname{PET}(t)$ including seasonal variabilities that are perfectly in-phase or perfectly out-of-phase. We also consider three different soil types: silty loam, sandy loam, and sand; assumed soil depths ranged from $6 \mathrm{~m}$ to $8 \mathrm{~m}$.

\section{Results}

\subsection{FDC separation into constituent elements}

Our goal in this paper is to use carefully defined rainfallrunoff simulations to elucidate the physical meaning of the

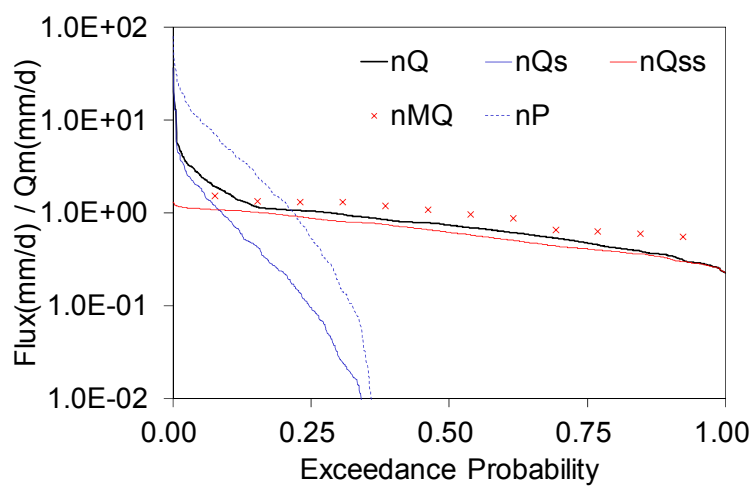

Fig. 2. An example of the decomposition of the flow duration curve normalized by mean annual daily flow $Q_{\mathrm{m}}$. " $n Q$ ", " $n Q_{\mathrm{s}}$ ", " $n Q_{\mathrm{ss}}$ ", " $n P$ " are normalized duration curves of daily flow, daily surface flow, daily subsurface flow, and daily precipitation; " $n M Q$ " is flow duration curve associated with the regime curve - ensemble averaged mean within-year daily flow variation normalized by mean annual daily flow $Q_{\mathrm{m}}$ ). We calculated exceedance probabilities for $n Q, n Q_{\mathrm{s}}, n Q_{\mathrm{ss}}$, and $n P$ as the order numbers sorted by their magnitudes for a total of 3 years divided by 1096 which is $365 \times 3+1$. For the exceedance probability of $n M Q$, we calculated the sorted order of the mean monthly flow divided by 13 which is $12+1$. Hence, precipitation and surface flow occurred about $1 / 3$ of the total calculation period and subsurface flow appeared every time period. Dryness index is 0.5 , and seasonal peaks of precipitation and potential evapotranspiration are in phase making a humid summer climate. Soil type is set as silty loam. Soil depth is $8 \mathrm{~m}$. Surface gradient is 0.006 .

shape of the FDC in terms of its underlying process controls. Figure 2 shows the result of a test run for a hypothetical watershed (with default parameters - slope gradient of 0.006 , soil type: silty loam, soil depth is $8 \mathrm{~m}$ ), in a humid climate with the seasonality of $P$ and PET that are in phase. In this case the FDC (thick black curve) is presented along with the surface flow duration curve (SFDC, thin blue curve) and the subsurface flow duration curve (SSFDC, thin red curve). We can clearly see that the upper tail of the FDC is quite close to that of the SFDC, whereas the middle section and the lower tail of the FDC track well the SSFDC. In addition, we can see that SFDC is a filtered version of the precipitation duration curve (PDC). Likewise we can see that the SSFDC closely tracks (is slightly below) the FDC of the mean monthly runoff (i.e. the regime curve). This is suggestive of the potential of constructing the middle part and lower tail of the FDC from the regime curve.

These results point to the decomposition of the FDC into two component building blocks: (i) the first component is a slightly filtered version of precipitation, which preserves the intermittence of the original time series, and (ii) a second component is a highly smoothed one, representing the result of a competition between subsurface drainage and evapotranspiration. The conceptual understanding of the shape of a FDC that we have assumed here agrees with findings in the 
literature as well (e.g. Vogel and Fennessey, 1995; Smakhtin, 2001; Castellarin et al., 2004a).

In the sections below we will present results of simulations for several combinations of climate and soils to confirm that the breakdown suggested above remains valid in all or most cases. If these features persist for all combinations of climate and landscape properties, this would then present an elegant and physically meaningful way to perform the separation of the FDC into its two component building blocks. In addition, we will explore the climatic and landscape (i.e. soils) controls on the two building blocks.

\subsection{Sensitivity of the FDC to climate factors}

The initial set of simulations involves different combinations of climate variability, which are the principal drivers of runoff variability. As shown in Fig. 3 four different cases are considered. Two different values of climatic dryness (defined as PET/P) are assumed, namely 0.5 (humid) and 1.5 (arid), to be consistent with the literature (i.e. Farmer et al., 2003; Mohamoud, 2008). In each case, two different types of seasonality are assumed, i.e. in-phase and out-of-phase seasonality of $P$ and PET. Apart from these default values of soil type (silty loam), a soil depth of $8 \mathrm{~m}$, and the topographic gradient of 0.006 are assumed. Figure $3 a, c$ and e are for the case for in-phase seasonality, whereas Fig. 3b, $\mathrm{d}$ and $\mathrm{f}$ are for out-of-phase seasonality. Figure $3 \mathrm{c}$ and d present the FDCs for surface runoff, whereas Fig. $3 \mathrm{e}$ and $\mathrm{f}$ present the FDCs for subsurface runoff.

Figure $3 \mathrm{a}$ and $\mathrm{b}$ present the FDCs for $R=0.5$ (humid) and 1.5 (arid), and the corresponding FDCs for the subsurface flow component (SSFDC) where $P$ and PET are in phase a and out-of-phase b. The results show that, in both cases, the middle section and the lower tail of the FDCs very well track the SSFDC. The FDCs deviate from the SSFDCs towards the upper tail, which is suggestive of surface runoff component. This leads to the FDCs of the surface runoff component (SFDC), which are presented in Fig. $3 \mathrm{c}$ and d, along with the FDCs of the precipitation inputs (PDC). The results reflect the presence of an infiltration loss, with a larger loss term in the arid case, and a smaller loss in the humid case, with seasonality not having a significant impact. The transformation between the PDC and SFDC are suggestive of a nonlinear (threshold) filter.

Figure $3 \mathrm{e}$ and $\mathrm{f}$ present the model generated FDC for subsurface runoff (SSFDC) for both $R=0.5$ and $R=1.5$. Along with these, we also present the corresponding FDCs associated with the simulated regime curve. The results indicate that the FDCs derived from the regime curve approximate the SSFDCs in a humid climate, regardless of climatic seasonality. However, in the arid climate where ET becomes the dominant process, the SSFDCs deviate from the FDCs derived from the regime curves, especially for low flows, resulting in a sharp dip in the FDCs towards the lower tail. Indeed, in arid climate with out-of-phase seasonality, there is a slight dip in the FDC of the regime curve as well towards the lower tail. The difference between the FDCs and the monthly runoff FDC (equivalent to the regime curve) is due to the presence or absence of temporal averaging. We would need an additional transfer function to reproduce the shape of the lower part of a FDC from the FDCs of monthly runoff (i.e. regime curve).

\subsection{Sensitivity of the FDCs to soil type}

Figure 4 shows the results of sensitivity analyses with respect to soil type and climatic seasonality (in-phase and outof-phase). Otherwise, these simulations use default values of climate dryness of $R=0.5$ (humid), a soil depth of $8 \mathrm{~m}$ and a topographic gradient of 0.006. As shown in Fig. 4 four different cases are considered: sand vs. silty loam (sandy soils with intermediate hydraulic properties are omitted for simplicity), and in-phase vs. out-of-phase seasonality. Figure 4a, c and e are for the case for in-phase seasonality, whereas Fig. 4b, $\mathrm{d}$ and $\mathrm{f}$ are for out-of-phase seasonality. Figure $4 \mathrm{c}$ and $\mathrm{d}$ present the FDCs for surface runoff, whereas Fig. 4e and $\mathrm{f}$ present the FDCs for subsurface runoff.

Figure $4 \mathrm{a}$ and $\mathrm{b}$ present the FDCs for two different types of soil (sand and silty loam), and the corresponding FDCs for the subsurface flow component (SSFDC). The results show that, in both cases, the middle section and the lower tail of the FDCs almost perfectly track the SSFDC. The FDC for sand deviates from that for silty loam in the lower tail in the case of in-phase seasonality; the deviations are much more in the case of out-of-phase seasonality. In either case, the net result is that the FDC for sand is steeper than those for silty loam. These results suggest that a combination of out-of-phase seasonality and well drained soils push the response towards ephemeral systems. The FDCs deviate from the SSFDCs towards the upper tail for silty loam (suggesting that the deviation is due to surface runoff due to infiltration excess runoff). Interestingly, in the case of sand, there is very little deviation between the FDC and SSFDC for the entire range of flows, suggesting that subsurface flow makes a contribution to high flows as well. This leads us to look at the FDCs of the surface runoff component (SFDC), which are presented in Fig. $4 \mathrm{c}$ and d, along with the FDCs of the precipitation inputs (PDC). The difference reflects infiltration loss, with larger loss in sand.

Figure $4 \mathrm{e}$ and $\mathrm{f}$ present the model generated FDCs for subsurface runoff (SSFDC) along with the corresponding FDCs associated with the regime curve. The results indicate that the FDCs derived from the regime curve nicely track the SSFDCs in a humid climate, regardless of climatic seasonality. However, in the case of out-of-phase seasonality, the FDCs for sand deviate from those for silty loam.

The effects of soil type obtained above are similar to what was obtained by Smakhtin (2001), Mohamoud (2008), and Botter et al. (2009). The above results can also be compared to those reported in Ward and Robinson (1990; Fig. 7.28) 
In-phase

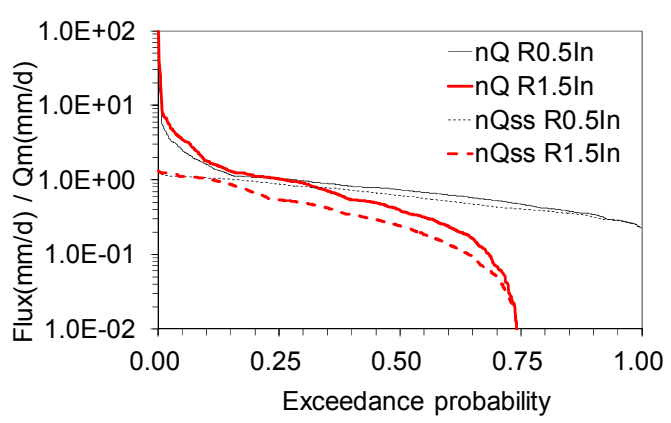

(a) total

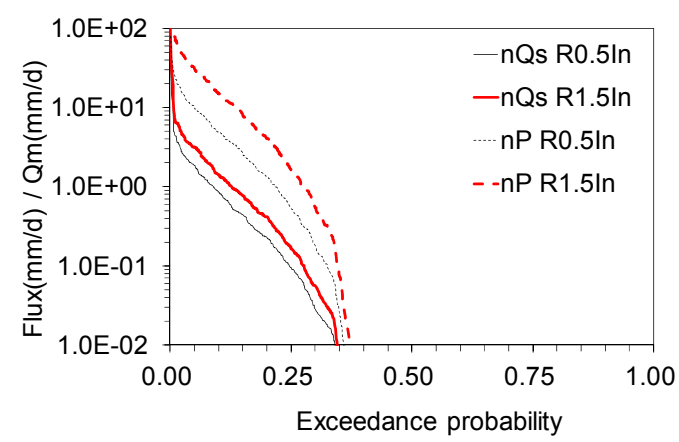

(c) surface

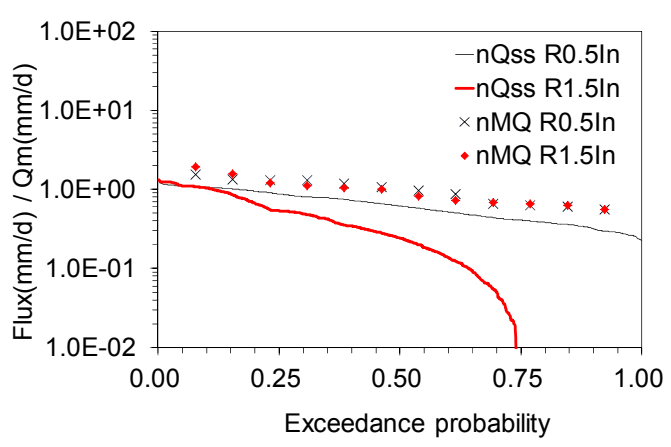

(e) subsurface

\section{Out-of-phase}

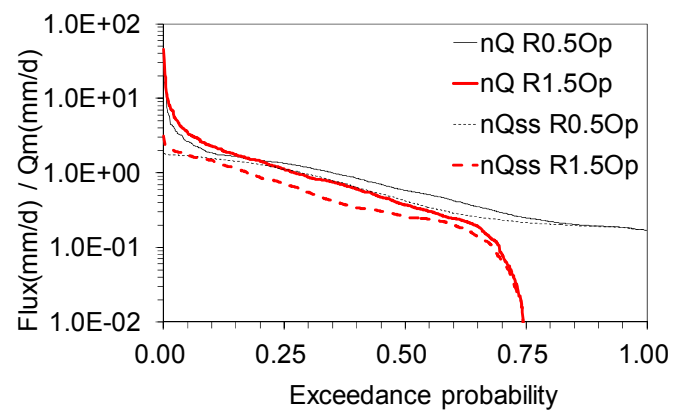

(b) total

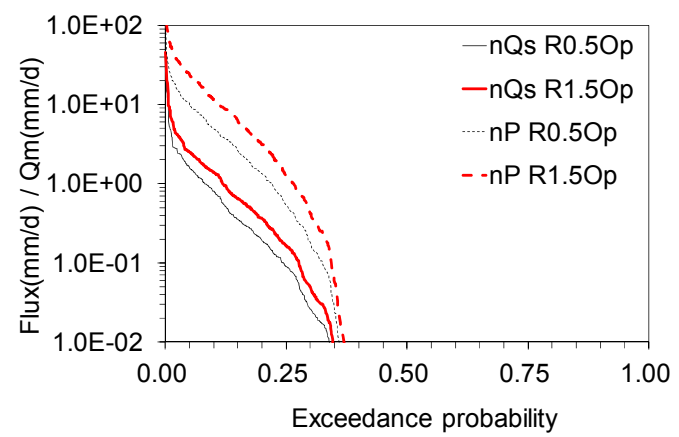

(d) surface

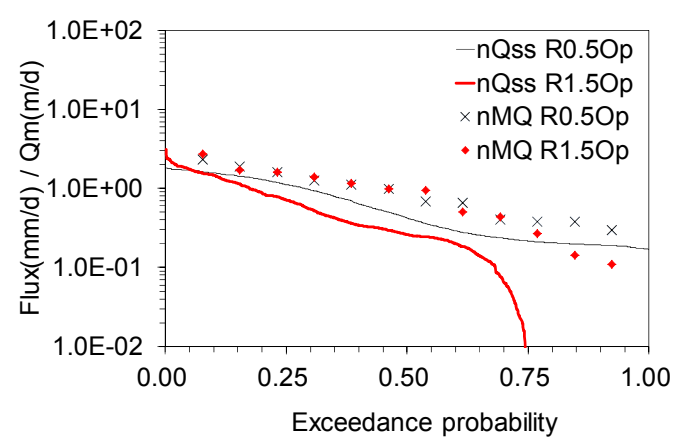

(f) subsurface

Fig. 3. Effect of dryness index $R$ on the FDC for different types of climatic seasonality: (a), (b): Total flow FDC, (c), (d):surface flow FDC, (e), (f): subsurface flow FDC. (a), (c), (e): seasonal peaks of $P$ and PET are in phase, (b), (d), (f): seasonal peaks of $P$ and PET are of opposite phase. The numbers after $R$ are dryness indices. In each panels, "In" and "Op" indicates $P$ and PET are in-phase and of out-of-phase, respectively. $Q_{\mathrm{m}}$ is mean annual daily flow $\left(\mathrm{mm} \mathrm{d}^{-1}\right)$. " $n M Q$ " refers to FDC associated with the regime curve - ensemble averaged mean within-year daily variation normalized by mean annual daily flow $Q_{\mathrm{m}}$. Default value of soil type is silty loam, soil depth is $8 \mathrm{~m}$, and the topographic gradient is 0.006 .

and Holmes et al. (2002). Ward and Robinson (1990) and Holmes et al. (2002) presented the FDCs for catchments in clay soils and chalk. Clay has low hydraulic conductivity and high porosity, and chalk has the opposite properties; the empirical results in Ward and Robinson (1990) and Holmes et al. (2002) indicate that soils with low hydraulic conductivity and high porosity generate steeper FDCs, and vice versa. This seems to contradicts our results shown in Fig. 4, where we predicted that FDC for sand would be steeper than for silty loam. It is possible, and this is speculation, that this 
In-phase

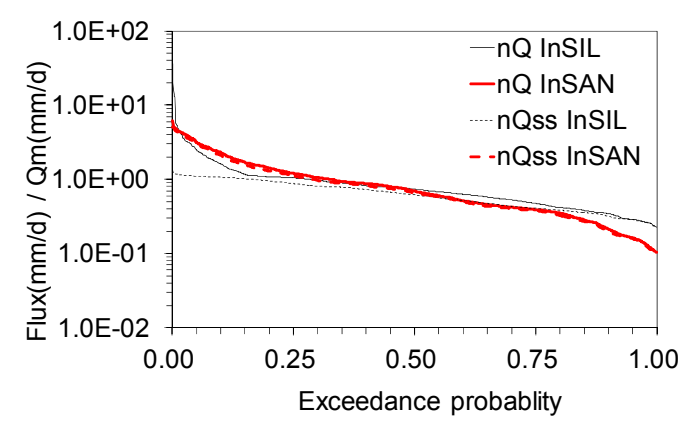

(a) total

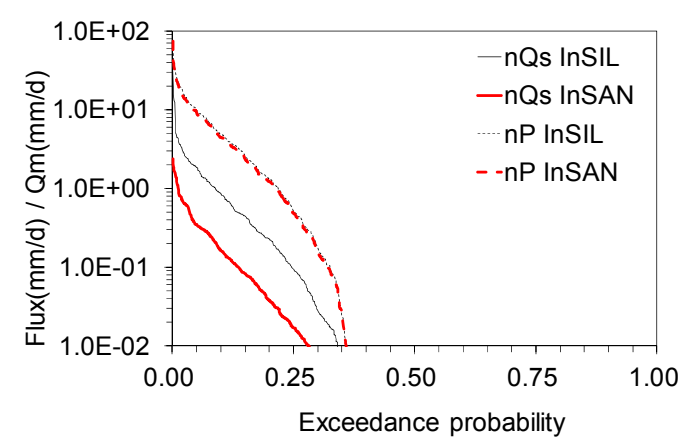

(c) surface

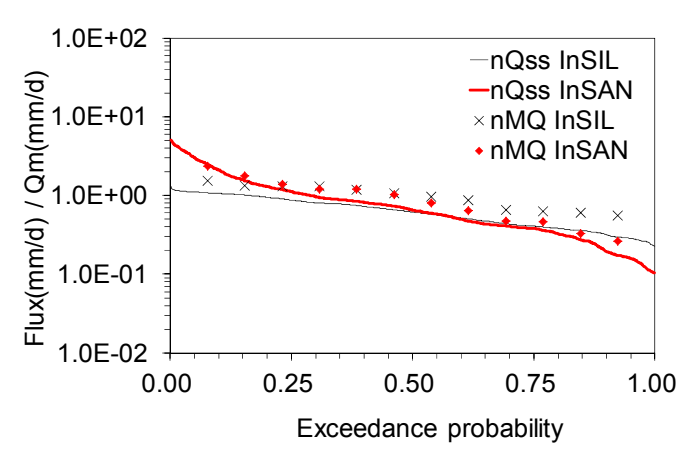

(e) subsurface
Out-of-phase

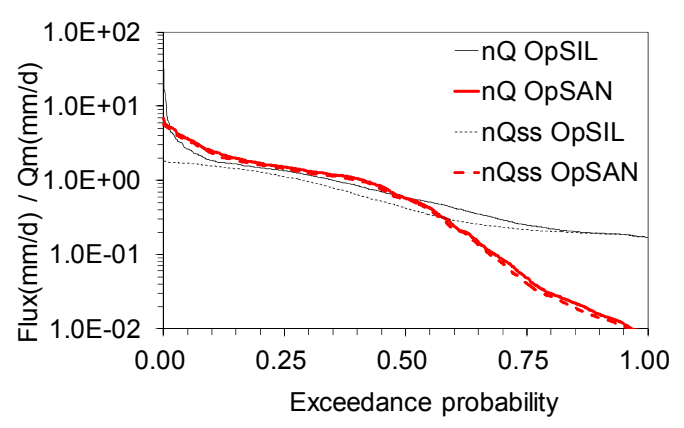

(b) total

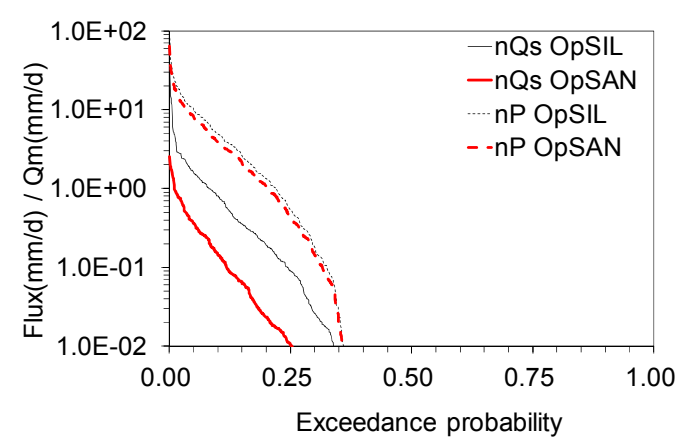

(d) surface

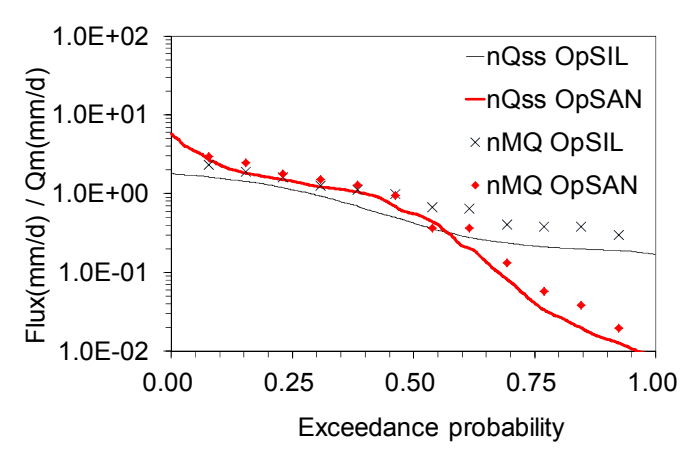

(f) subsurface

Fig. 4. Effect of soil type for different climatic seasonality: (a), (b): Total flow FDC, (c), (d): surface flow FDC, (e), (f): subsurface flow FDC. (a), (c), (e): seasonal peaks of $P$ and PET are in phase, (b), (d), (f): seasonal peaks of $P$ and PET are of opposite phase. "SAL" and "SAN" indicate silty loam and sand. $Q_{\mathrm{m}}$ is mean annual daily flow $\left(\mathrm{mm} \mathrm{d}^{-1}\right)$. " $n M Q$ " refers to FDC associated with the regime curve ensemble averaged mean within-year daily variation normalized by mean annual daily flow $Q_{\mathrm{m}}$. Default value of climate dryness is $R=0.5$ (humid), soil depth is $8 \mathrm{~m}$ and a topographic gradient is 0.006 .

contradiction may be explained by the presence of macropores or other kind of biotically influenced preferential pathways in real basins, which are not explicitly included in our simple, theoretical model. Hence our results on the effects of soil type on the FDCs have to remain as a hypothesis to be eventually tested against observed data in the future.

\subsection{Sensitivity of the FDCs to soil depth}

Figure 5 shows the results of sensitivity analyses with respect to soil depth and climatic seasonality (in-phase and out-ofphase), with default values of climate dryness of $R=0.5$ (humid), silty loam, and a topographic gradient of 0.006. As can 
In-phase

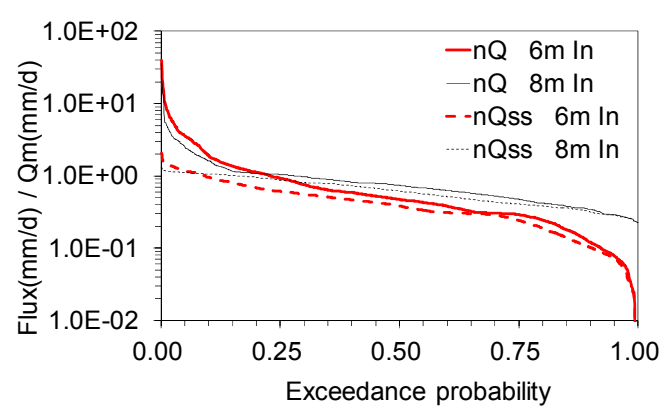

(a) total

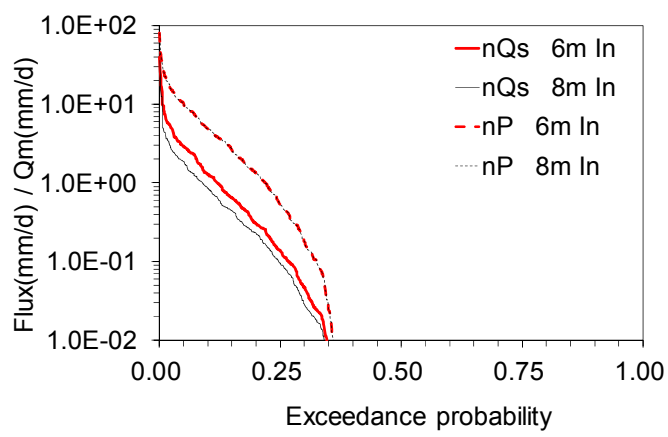

(c) surface

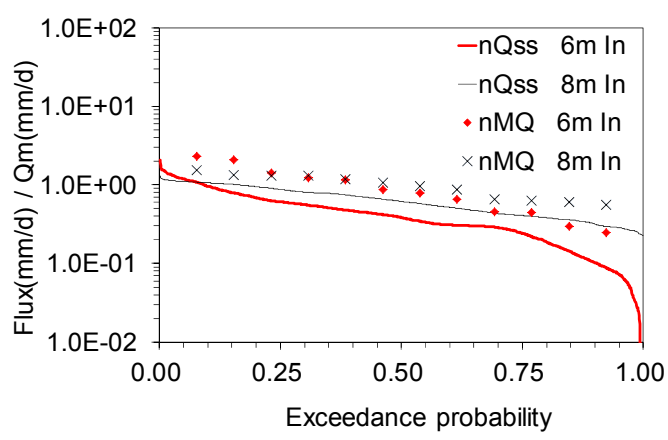

(e) subsurface
Out-of-phase

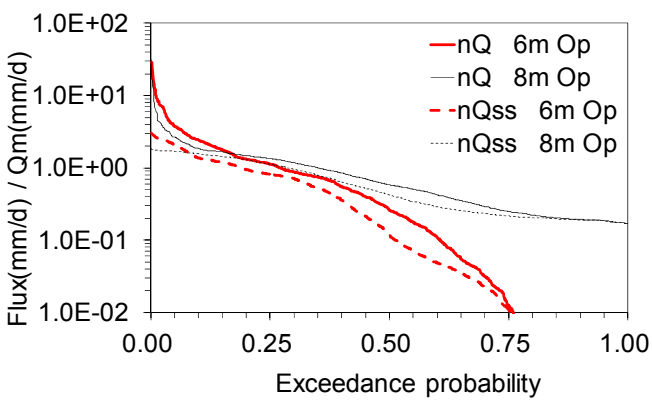

(b) total

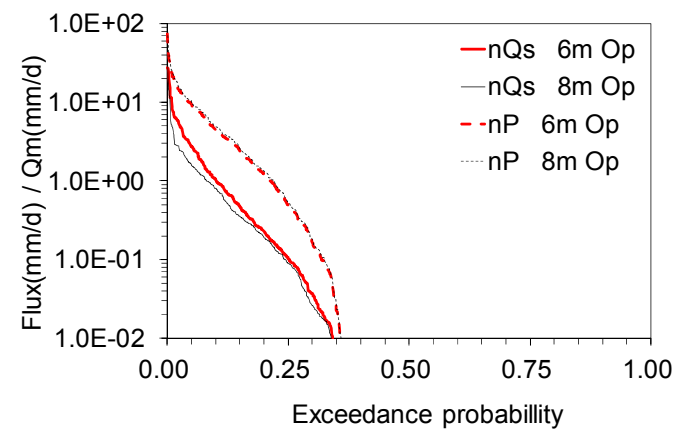

(d) surface

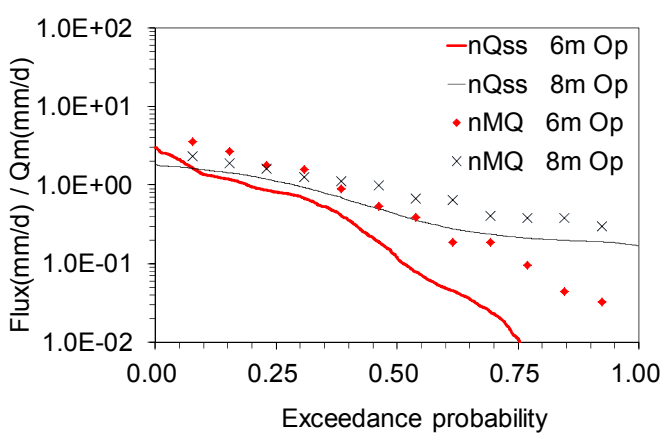

(f) subsurface

Fig. 5. Effect of soil depth for different climatic seasonality: (a), (b): Total flow FDC, (c), (d): surface flow FDC, (e), (f): subsurface flow FDC. (a), (c), (e): seasonal peaks of $P$ and PET are in phase, (b), (d), (f): seasonal peaks of $P$ and PET are of opposite phase. The " $6 \mathrm{~m}$ " and " $8 \mathrm{~m}$ " indicate soil depth for each experimental case. $Q_{m}$ is mean annual daily flow $\left(\mathrm{mm} \mathrm{d}^{-1}\right)$. " $n M Q$ " refers to FDC associated with the regime curve - ensemble averaged mean within-year daily variation normalized by mean annual daily flow $Q_{\mathrm{m}}$. Default value of climate dryness is $R=0.5$ (humid), soil type is silty loam, and topographic gradient is 0.006 .

be seen in Fig. 5, four different cases are considered: two different soil depths $(6 \mathrm{~m}$ and $8 \mathrm{~m})$, and in-phase and outof-phase seasonality. Figure 5a, c and e are for in-phase seasonality, and Fig. 5b, d and $\mathrm{f}$ are for out-of-phase seasonality. Figure $5 \mathrm{c}$ and $\mathrm{d}$ present the FDCs for surface runoff, whereas Fig. 5e and $f$ present the FDCs for subsurface runoff.
Figure 5a and $\mathrm{b}$ indicate that SSFDCs closely approximate the FDCs in the middle region and lower tail, in all four cases. However, the FDCs for shallow soil are steeper than for deep soil, with the steepness being bigger in the case of out-of-phase seasonality. This is suggestive of the roles of ET and storage capacity of soil: shallow soils lends itself 
to generate partial saturated areas where ET is larger due to the moisture being more accessible to the influence of atmospheric demand while there is more chance for surface runoff to be generated over partial saturated areas as well. Note also that there is a deviation between the FDCs and SSFDCs at the upper tail. As before, this being a silty loam, the discrepancy is due to surface runoff contribution. This is also reflected in Fig. 5c and d; as before, the FDCs for surface runoff track PDC. However, since the surface runoff (especially by infiltration excess) is a surface phenomenon, it is not affected by the depth of soil.

Figure 5e and $\mathrm{f}$ present a comparison between the SSFDCs and the FDCs derived from the regime curve. The results indicate that the SSFDCs generally track the FDCs generated from the regime curve, especially when the soil is deep. However, there is a deviation towards the lower tail of the FDCs, and the deviation is larger in the case of out-of-phase seasonality. One can also see that the FDC generated from the regime curves also deviate in shallow soils from that for deep soils during low flows, which becomes even more significant when $P$ and PET are out of phase. Hence the estimation of SSFDC and FDC from mean monthly runoff (regime curve) would not be not so straightforward for basins with shallow soils. This is because shallow soil has smaller storage capacity and hence runoff is sensitive to precipitation and evapotranspiration. If precipitation stops, then ET would become more dominant during such dry periods as shown by Botter et al. (2007a,b). These observations lead us to the idea that ET may be playing a dominant role under dry conditions, as also highlighted in Figs. 3 and 4.

\subsection{Possible reason for lower tail of the FDCs}

Through Figs. 3 to 5, we have shown that the SSFDCs deviated from the FDCs generated from the regime curve under arid climate and shallow soil, and it was difficult to reproduce the shape of middle to lower flow parts of a FDC. In order to understand the possible reasons for the sharp dip of the FDC under arid climates and in shallow soils, we constructed the flow duration curves for outflows OF from the saturated zone along with the corresponding SSFDCs. In the model, subsurface flow $Q_{\mathrm{ss}}$ is calculated as outflow OF minus the product of saturated surface area fraction and ET from that saturated surface (which happens at the potential rate PET: indeed, when the product is higher than $\mathrm{OF}$, then $Q_{\text {ss }}$ is put to zero and the product becomes equal to $\mathrm{OF}$.) Therefore, any differences between the duration curves for OF and $Q_{\mathrm{ss}}$, and the dip in the SSFDCs at low flows are potentially due to the ET from the saturated surface areas, and the temporal smoothing involved in constructing the regime curve.

The results are presented in Fig. 6. Panels a and b show the results for different climatic dryness and seasonality. Panels $a$ and $c$ are for in-phase seasonality, and panels $b$ and $d$ are for out-of-phase seasonality. Default value of soil type is silty loam, soil depth is $8 \mathrm{~m}$, the topographic gradient is 0.006 , and dryness index is 0.5 . Through these results we assess the controls on the deviations by exploring the effects of climate dryness in panels a and $b$, and the effects of soil depth in panels $\mathrm{c}$ and $\mathrm{d}$. The results confirm that even when $\mathrm{OF}$ is non-zero during dry periods, the FDC for subsurface flows deviate downwards at low flow conditions, reaching zero for some $25 \%$ of the time in arid catchments, which is caused by ET from partial saturated areas. We can also find that the slope of OF is high and the deviation is less during low $Q_{\mathrm{ss}}$ periods if $P$ and PET are out of phase under arid climate, which reflects the seasonality of such climate where there is more chance of infiltration to the saturated zone during wet seasons to generate relatively sustained $Q_{\text {ss. }}$. By comparing the results in the panel $\mathrm{c}$ and $\mathrm{d}$, we can notice that the deviation of $Q_{\mathrm{ss}}$ from OF is higher if $P$ and PET are out of phase and/or soil depth is shallow. If a basin's soil is shallow, water table appears close to the ground surface and the saturated surface area fraction increases. In addition, ET from the saturated surface becomes more dominant helping to expand the deviation when $P$ and PET are out of phase.

As shown here, the dip of a FDC under arid climates or shallow soils is potentially due to the dominance of ET from the saturated areas. In such basins, we would observe very little subsurface runoff (i.e. zero flows) for some period in a year, which causes the ephemeral runoff time series, making them different from the FDCs associated with mean monthly runoff (regime curve). Hence it would be difficult to estimate the FDC from a regime curve alone and it will be necessary to introduce a more sophisticated rainfall-runoff model to estimate the shape of FDC. On the other hand, we would have more chance to reproduce the shape of a FDC from a regime curve if the basin is in a humid climate or has deep soils.

\section{Discussion and conclusions}

The flow duration curve represents the distillation of intraannual variability of runoff, and presented in the frequency (probability) domain. It can be seen as a manifestation of the filtering by the catchment of within-year variability of precipitation. Precipitation variability comprises variability at a range of scales, including random within-storm and betweenstorm variability as well as more systematic (e.g. seasonal) variability. In this paper we investigated the effects of climate, soils, and topography on the shape of the FDC using a simple, physically based water balance model and synthetic rainfall data. The study focused on the fundamental questions: what does the shape of the FDC represent, and what are its process controls?

Despite the fact that the exploration of these questions was based on model simulations in hypothetical watersheds, they did produce important results and revealed new insights that are consistent with our physical intuition as embedded in the rainfall-runoff model. We found that the slope of the FDCs is strongly affected by the nature of seasonality of the climate 
In-phase

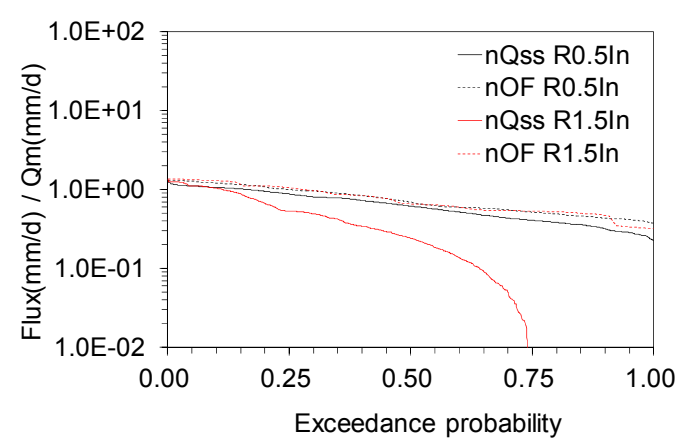

(a)

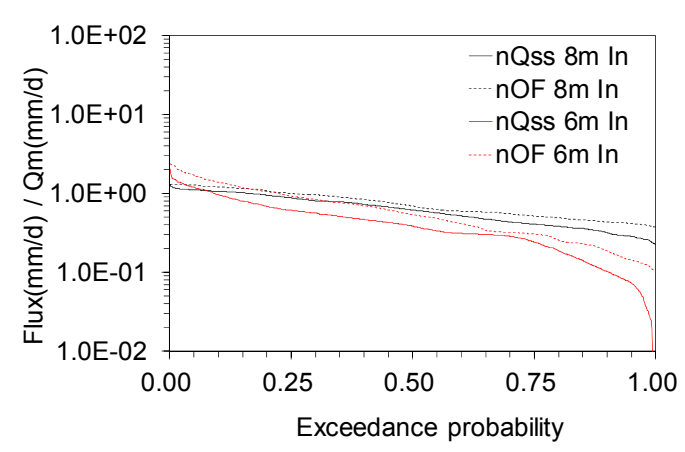

(c)

\section{Out-of-phase}

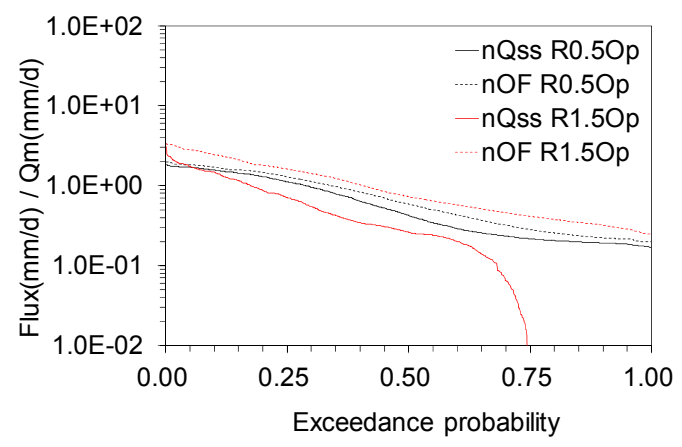

(b)

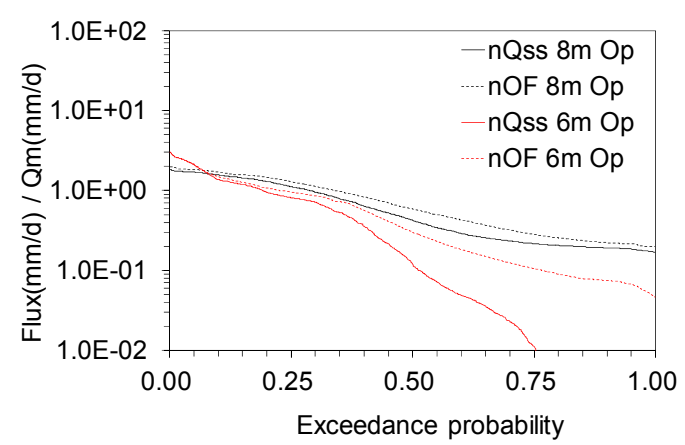

(d)

Fig. 6. Relationships between FDCs of the outflow OF and subsurface flow $Q_{\mathrm{ss}}$ normalized by mean annual daily flow $Q_{\mathrm{m}}$ : (a) seasonal peaks of $P$ and PET are both in phase but dryness indices are 0.5 and 1.5 ; (b) seasonal peaks of $P$ and PET are both of opposite phase and dryness indices are 0.5 and 1.5; (c) seasonal peaks of $P$ and PET are both in phase but soil depths are $6 \mathrm{~m}$ and $8 \mathrm{~m}$; and (d) seasonal peaks of $P$ and PET are both of opposite phase but soil depth is $6 \mathrm{~m}$ and $8 \mathrm{~m}$. The difference between $Q_{\mathrm{m}}$ and OF is equal to the evapotranspiration from the saturated fraction of the ground surface. Default soil type, soil depth, topographic gradient, and dryness index are, respectively, silty loam, $8 \mathrm{~m}, 0.006$, and 0.5 .

drivers: precipitation and potential evaporation. The FDC is steeper when the seasonality of $P$ and PET are out of phase, in comparison to when they are in phase. In addition, the slope of the FDC is further enhanced in more permeable soils and in shallow soils. On the other hand, the effect of climate is such that with increasing aridity the flow becomes more ephemeral, with the result that the FDC tends to get cut off at low flows.

The results indicated that there is considerable potential to estimate the shape of a FDC in its middle and low flow parts from mean monthly runoff (regime curve) in basins under humid climate with relatively deep soils. However, in arid climates or catchments with shallow soils that tend to generate ephemeral runoff, it is difficult to reproduce the shape of a FDC from the regime curve alone. To reproduce the shape of a FDC from a regime curve in circumstances where the effect of ET is strong (i.e. arid climate, shallow soils, out-of-phase seasonality), we need to explicitly consider a correction to the middle and lower tail to account for the reduction of subsurface drainage due to the effects of ET losses over the near-stream saturation areas. We would need a more sophisticated model including estimating ET losses, and incorporating complex processes such as seasonal changes in leaf phenology.

Figure 7 presents a schematic that describes the conceptual understanding that we have gained from these model simulations, as a hypothesis that needs to be rigorously tested with the use of observed data. Figure 7 highlights three components to the shape of the FDC: a surface runoff component SFDC, a subsurface component SSFDC, and a correction to account for the effects of ET from near-stream saturation areas that impact the lower tail of the FDC. The model simulations showed that the SFDC component closely tracks the FDC of within-year precipitation variability (PDC). The transformation from PDC to SFDC reflects the effects of infiltration losses, a climate/soil dominated, 


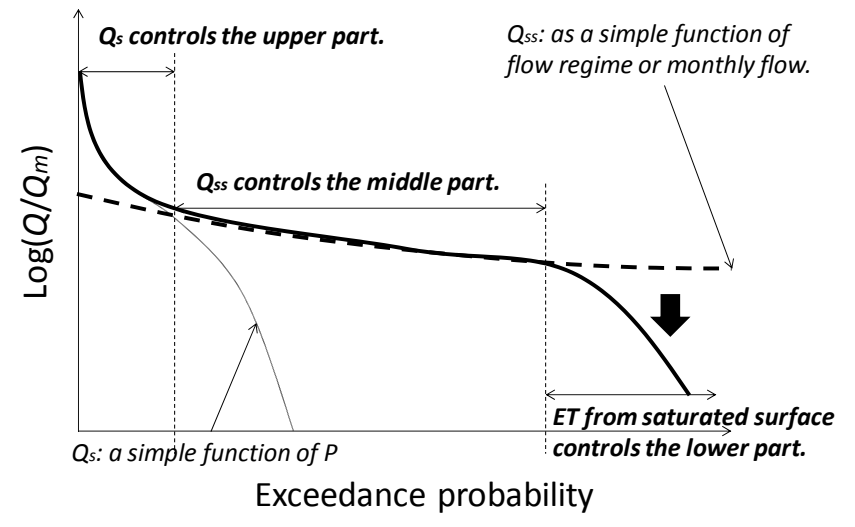

Fig. 7. Schematic illustrating the understanding gained through this simulation study regarding the shapes of the flow duration curve, including the controls on the different parts of the FDC.

surface phenomenon that can be captured using a nonlinear (threshold) filter. The dominant factors that control it are rainfall intensity patterns and soil (infiltration) characteristics, with very little influence of climate seasonality, soil depth or surface topography.

The SSFDC component, in most cases, is a much more smoothed component, with much of the event structure smoothed out. Instead, the shape of the SSFDC reflects the competition between seasonal variability of precipitation and potential evapotranspiration in the vadose zone, which governs recharge to the water table, and then the filtering of the groundwater recharge flux by the dynamic aquifer through subsurface drainage. Previous work has explored the process controls on the recharge (Struthers et al., 2006; McGrath et al., 2007; Harman et al., 2011), and on shallow subsurface flow in hillslopes (Harman and Sivapalan, 2009).

Finally the dip of the flow duration curve at the lower tail arises due to the relatively higher ET from saturated surfaces, which happens in watersheds in arid climates or with lower storage capacity of soil. This is a feature that we could capture with a quasi-2-D model that pays explicit attention to the water table profile and its intersection with the land surface. The main process controls are, therefore, topography, landscape organization, depth to bedrock, and lateral saturated hydraulic conductivity.

On the basis of these considerations we are now in a position to formulate a conceptual framework for the reconstruction of the flow duration curve in ungauged basins. This is presented in Fig. 8. The conceptual framework comprises three components: (1) a simple nonlinear (threshold) filter model that captures surface infiltration losses, and in this way provide the transformation from PDC to SFDC; (2) estimation of the middle to lower flow parts of a FDC from a mean monthly runoff data in basins with perennial runoff. Mean monthly runoff is relatively easy to obtain from global runoff simulation model results or through extrapolation from measured data in gauged basins. If the basin generates ephemeral

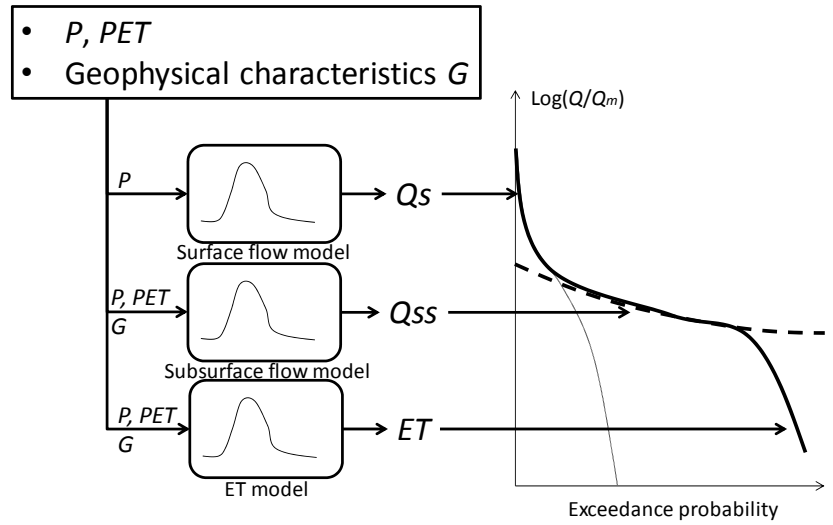

Fig. 8. A conceptual model for reconstruction of the flow duration curves in ungauged basins, consisting of models of (i) partitioning of precipitation into fast (surface) runoff and wetting, which involves nonlinear (threshold filtering), (ii) the partitioning of the wetting into slow (subsurface) flow and evapotranspiration, which involves mainly linear filtering, and (iii) a correction to the FDC in flow situations due to evapotranspiration from saturated areas.

runoff, we would need to introduce a more complex two component model of the vadose zone coupled to a subsurface flow model, as a way to simulate realistic patterns of recharge to the water table and then its filtering in the shallow aquifer below; and (3) finally, we need a 2-D model in order to simulate the dynamics of the near-stream saturated area so that we can estimate ET correction during low flow periods. Note that details for the nonlinear filter model of the above (1), a simple two component model of the vadose zone coulped to a shallow subsrface flow model of the above (2), and a 2-D model of the near stream saturated area of the above (3) must be constructed and parameterized for each basin; this forms part of our future work.

The insights gained into the shapes of FDCs, including their process controls, give us confidence that there is considerable potential for extrapolating the shapes of FDCs from daily precipitation data, monthly flow data, climatic dryness and storage capacity in gauged basins to ungauged basins, at least, in humid basins. Work being undertaken by the authors is aimed at implementing the conceptual framework developed here in over 200 catchments around the continental United States, and using the data from these catchments to explore the spatial (regional) patterns of variations of the FDCs across the country, explain these patterns on the basis of available evidence on climate, soils and topography, and evaluate the power of the conceptual framework developed here to extrapolate FDCs from gauged basins to ungauged basins.

In Fig. 9, we present preliminary results from 3 of the 200 MOPEX catchments. The three catchments chosen are located in diverse climatic regions: Idaho and North Carolina. Here we present the FDCs for precipitation, surface runoff, subsurface runoff, as well total runoff and the FDCs 

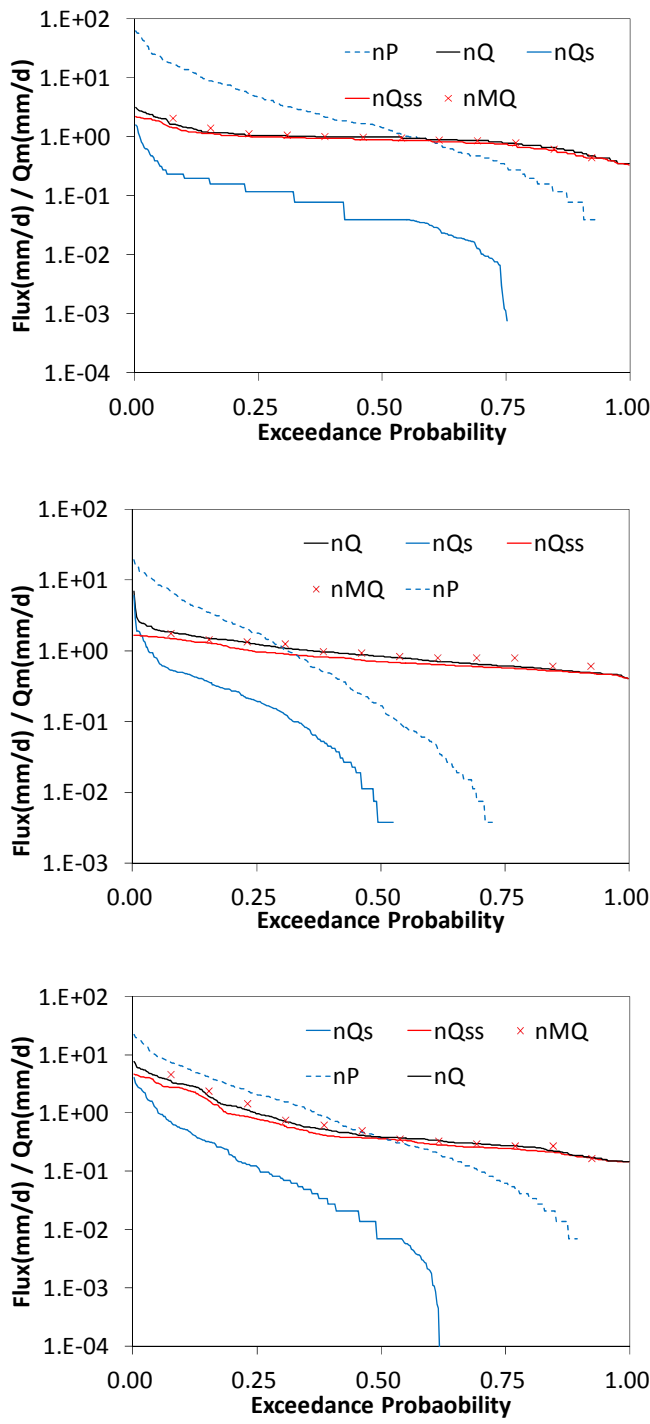

Fig. 9. Three example applications of the concepts derived from this paper: Relationships among duration curves of precipitation $(n P)$, total runoff $(n Q)$, surface runoff $\left(n Q_{\mathrm{S}}\right)$, subsurface runoff $\left(n Q_{\mathrm{ss}}\right)$, all at daily time scales and normalized by annual mean daily flow $\left(Q_{\mathrm{m}}\right)$ along with mean monthly runoff $(n M Q)$ at daily time scale normalized by annual mean daily flow $\left(Q_{\mathrm{m}}\right)$. (a) data from MOPEX watershed \#86, Salmon River at Salmon, Idaho, (b) data from MOPEX watershed \#237, Nantahala River near Rainbow Springs, North Carolina, and (c) data from MOPEX watershed \#323, Lochsa River near Lowell, Idaho.

estimated from the "regime curve" (mean monthly variation of total runoff). The surface and subsurface runoff components are estimated using a baseflow separation algorithm (Lyne and Hollick, 1979), which was previously summarized in Sivapalan et al. (2011). These results provide some confirmation of the conclusions of this paper. In particular, one can see the close relationship between the PDCs and SFDCs, and the similarly strong relationships between the SSFDCs and the FDCs associated with the regime curves. As shown above, we have confidence that the understandings gained on the process controls of FDCs, as outlined in the proposed framework for their reconstruction in ungauged basins would have considerable potential for broad applications in the future.

Acknowledgements. The first author is grateful for the financial support provided by the JSPS Research Fellowship for Young Scientists and the Grant-in-Aid for JSPS fellows that enabled the long-term collaboration that culminated in the publication of this paper. He also thanks the Grant-in-Aid for Young Scientists (B, 18760381, 21760381), Grant-in-Aid for Scientific Research (B, 22360192, PI: Prof. So Kazama at Tohoku University, Japan), research grant from Maeda Engineering Foundation, Environment Research and Technology Development Fund (S-8-1(4)) of the Ministry of the Environment, Japan, and the Science and Technology Research Partnership for Sustainable Development, JST-JICA, Japan, for providing additional support. The present study was also supported by "Wisdom of Water" (Suntory) Corporate Sponsored Research Program at the University of Tokyo, provided by the Suntory Corporation, Japan. The authors are also grateful to Taikan Oki of the University of Tokyo for his constructive comments on earlier drafts of this paper.

Edited by: P. Claps

\section{References}

Botter, G., Porporato, A., Daly, E., Rodriguez-Iturbe, I., and Rinaldo, A.: Probabilistic characterization of base flows in river basins: Roles of soil, vegetation, and geomorphology, Water Resour. Res., 43, W06404, doi:10.1029/2006WR005397, 2007a.

Botter, G., Peratoner, F., Porporato, A., Rodriguez-Iturbe, I., and Rinaldo, A.: Signatures of large-scale soil moisture dynamics on streamflow statistics across U.S. Climate regimes, Water Resour. Res., 43, W11413, doi:10.1029/2007WR006162, 2007b.

Botter, G., Porporato, A., Rodriguez-Iturbe, I., and Rinaldo, A.: Nonlinear storage-discharge relations and catchment streamflow regimes, Water Resour. Res., 45, W10427, doi:10.1029/2008WR007658, 2009.

Bras, R. L.: Hydrology - An Introduction to Hydrologic Science, Addison-Wesley- Longman, Reading, Mass., 1990.

Brooks, R. H. and Corey, A. T.: Properties of porous media affecting fluid flow, J. Irrig. Drain. Div. Am. Soc. Civ. Eng., IR2, 61-88, 1966.

Brutsaert, W.: Probability laws for pore-size distributions, Soil Sci., 101, 85-92, 1966.

Budyko, M. I.: Climate and Life, Academic Press, New York, 1974.

Burt, T. P. and Swank, W. T.: Flow frequency responses to hardwood-to-grass conversion and subsequent succession, Hydol. Process., 6, 179-188, 1992.

Castellarin, A., Vogel, R. M., and Brath, A.: A stochastic index flow model of flow duration curves, Water Resour. Res., 40, W03104, doi:10.1029/2003WR002524, 2004a.

Castellarin, A., Galeati, G., Brandimarte, L., Montanari, A., and Brath, A.: Regional flow-duration curves: reliability for ungaged basins, Adv. Water Resour., 27, 953-965, 2004b. 
Chow, V. T., Maidment, D. R., and Mays, L. W.: Applied Hydrology, McGraw-Hill, New York, 1988.

Farmer, D., Sivapalan, M., and Jothityangkoon, C.: Climate, soil, and vegetation controls upon the variability of water balance in temperate and semi-arid landscapes: Downward approach to water balance analysis, Water Resour. Res., 39, 1035, doi:10.1029/2001WR000328, 2003.

Harman, C. J. and Sivapalan, M.: Similarity framework to assess controls on subsurface flow dynamics in hillslopes, Water Resour. Res., 45, W01417, doi:10.1029/2008WR007067, 2009.

Harman, C. J., Rao, P. S. C., Basu, N. B., McGrath, G. S., Kumar, P., and Sivapalan, M.: Climate, soil and vegetation controls on the temporal variability of vadose zone transport, Water Resour. Res., doi:10.1029/2010WR010194, in press, 2011.

Holmes, M. G. R., Young, A. R., Gustard, A., and Grew, R.: A region of influence approach to predicting flow duration curves within ungauged catchments, Hydrol. Earth Syst. Sci., 6, 721731, doi:10.5194/hess-6-721-2002, 2002.

Huff, F. A.: Time distribution of rainfall in heavy storms, Water Resour. Res., 7, 1007-1018, 1967.

Iacobellis, V.: Probabilistic model for the estimation of $\mathrm{T}$ year flow duration curves, Water Resour. Res., 44, W02413, doi:10.1029/2006WR005400, 2008.

Kosugi, K.: Three-parameter lognormal distribution model for soil water retention, Water Resour. Res., 30, 891-901, 1994.

Koutsoyiannis, D. and Foufoula-Georgiou, E.: A scaling model of a storm hyetograph, Water Resour. Res., 29, 2345-2361, 1993.

Lee, H., Zehe, E., and Sivapalan, M.: Predictions of rainfall-runoff response and soil moisture dynamics in a microscale catchment using the CREW model, Hydrol. Earth Syst. Sci., 11, 819-849, doi:10.5194/hess-11-819-2007, 2007.

Li, H. and Sivapalan, M.: Effect of spatial heterogeneity of runoff generation mechanisms on the scaling behavior of event runoff responses in a natural river basin, Water Resour. Res., 47, W00H08, doi:10.1029/2010WR009712, 2011a.

Li, H., Sivapalan, M., and Tian, F.: Comparative diagnostic analysis of runoff generation processes in Oklahoma DMIP2 basins: The Blue River and the Illinois River, J. Hydrol., doi:10.1016/j.jhydrol.2010.08.005, in press, 2011b.

Lyne, V. and Hollick, M.: Stochastic time-variable rainfall-runoff. Proc. Hydrology and Water Resources Symposium, Perth, Inst. of Engrs. Australia, 89-92, 1979.

McGrath, G. S., Hinz, C., and Sivapalan, M.: Temporal dynamics of hydrological threshold events, Hydrol. Earth Syst. Sci., 11, 923-938, doi:10.5194/hess-11-923-2007, 2007.

Mohamoud, Y. M.: Prediction of daily flow duration curves and streamflow for ungauged catchments using regional flow duration curves, Hydrolog. Sci. J., 53, 706-724, doi:10.1623/hysj.53.4.706, 2008.
Muneepeerakul, R., Azaele, S., Botter, G., Rinaldo, A., and Rodriguez-Iturbe, I.: Daily streamflow analysis based on a twoscaled gamma pulse model, Water Resour. Res., 46, W11546, doi:10.1029/2010WR009286, 2010.

Musiake, K., Inokuti, S., and Takahashi, Y.: Dependence of low flow characteristics on basin geology in mountainous areas of Japan, IAHS Publ., 117, 147-156, 1975.

Reggiani, P., Sivapalan, M., and Hassanizadeh, S. M.: Conservation equations governing hillslope responses: Exploring the physical basis of water balance, Water Resour. Res., 36, 1845-1863, 2000.

Robinson, J. S. and Sivapalan, M.: Temporal scale and hydrological regimes: Implications for flood frequency scaling, Water Resour. Res., 33, 2981-2999, 1997.

Sefton, C. E. M. and Howarth, S. M.: Relationships between dynamic response characteristics and physical descriptors of catchments in England and wales, J. Hydrol., 211, 1-16, 1998.

Sivapalan, M., Yaeger, M. A., Harman, C. J., Xu, X., and Troch, P. A.: Functional model of water balance variability at the catchment scale: 1. Evidence of hydrologic similarity and space-time symmetry, Water Resour. Res., 47, W02522, doi:10.1029/2010WR009568, 2011.

Smakhtin, V. U.: Low flow hydrology: a review, J. Hydrol., 240, 147-186, 2001.

Struthers, I., Hinz, C., and Sivapalan, M.: A multiple wetting front gravitational infiltration and redistribution model for water balance applications, Water Resour. Res., 42, W06406, doi:10.1029/2005WR004645, 2006.

Vogel, R. M. and Fennessey, N. M.: Flow-duration curves I: New interpretation and confidence intervals, J. Water Resour. Pl.-ASCE, 120(4), 485-504, 1994.

Vogel, R. M. and Fennessey, N. M.: Flow-duration curves II: A Review of applications in water resources planning, Water Resour. Bull., 31(6), 1029-1039, 1995.

Ward, R. C. and Robinson, M.: Principles of Hydrology, 3rd Edn., McGraw-Hill, Maidenhead, Berkshire, England, 1990.

Yilmaz, K. K., Gupta, H. V., and Wagener, T.: A process-based diagnostic approach to model evaluation: Application to the NWS distributed hydrologic model, Water Resour. Res., 44, W09417, doi:10.1029/2007WR006716, 2008.

Yokoo, Y., Sivapalan, M., and Oki, T.: Investigating the roles of climate seasonality and landscape characteristics on mean annual and monthly water balances, J. Hydrol., 357, 255-269, 2008.

Zehe, E., Lee, H., and Sivapalan, M.: Dynamical process upscaling for deriving catchment scale state variables and constitutive relations for meso-scale process models, Hydrol. Earth Syst. Sci., 10, 981-996, doi:10.5194/hess-10-981-2006, 2006.

Zhang, G. P. and Savenije, H. H. G.: Rainfall-runoff modelling in a catchment with a complex groundwater flow system: application of the Representative Elementary Watershed (REW) approach, Hydrol. Earth Syst. Sci., 9, 243-261, doi:10.5194/hess-9-2432005, 2005. 